\title{
Study of the Stature Structure of 10-12 Years Old Female Students in Selected Elementary Schools in Tehran
}

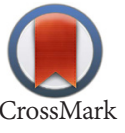

Leili Borimnejad $^{1^{*}}$, Nahid Salmanyazdi², Hamid Haghani ${ }^{3}$

1. Center for Nursing Care Research, Faculty of Nursing \& Midwifery, Iran University of Medical Sciences, Tehran, Iran.

2. Department of Pediatric Nursing, Faculty of Nursing \& Midwifery, Iran University of Medical Sciences, Tehran, Iran.

3. Department of Biostatistics, School of Public Health, Iran University of Medical Sciences, Tehran, Iran.

Crtation: Borimnejad, L, Salmanyazdi, N \& Haghani, H 2016, 'Study of the stature structure of 10-12 years old female students in selected elementary schools in Tehran', Journal of Client-Centered Nursing Care, vol. 2, no. 1, pp. 63-68. https://doi.org/10.32598/jccnc.2.1.63

: https://doi.org/10.32598/jccnc.2.1.63

Article info:

Received: 05 Sep. 2015

Accepted: 15 Dec. 2015

Keywords:

Stature, Female students, Skeletal disorders

\begin{abstract}
A B S T RA C T
Background: One of the common problems in early adolescence is skeletal disorders which has an international dimension to the extent that structural and postural abnormalities screening programs are in schools agenda in different countries for years. This study aimed to determine skeletal structure of female students aged 10 to 12 years in Tehran.

Methods: In this cross-sectional study after using cluster random sampling method, 283 students in fourth and fifth grades registered in academic year 2013-2014 were recruited. We investigated the skeletal structure of them by body analysis software, their demographic information by a questionnaires and their anthropometric characteristics by using standard scale. The obtained data were analyzed through descriptive statistical tests, the Chi-square test, and Kendall correlation coefficient using SPSS version 19.

Results: About $6 \%$ of students $(n=17)$ had no skeletal disorder and the rest suffered from at least one problem. Two students $(0.7 \%)$ suffered from 7 disorders simultaneously. The highest percentage of obesity (39.7\%) was seen in 12 years age group and the most frequent underweight $(8.2 \%)$ was observed in 14 students in the age group of 10 years. About $1.8 \%$ of subjects $(n=5)$ suffered from forward head disorder. Also, $5.7 \%$ of children $(n=16)$ suffered from hallux valgus. The Chi-squared statistical analysis showed that there is a significant relationship between hallux valgus disorder and age $(\mathrm{P}=0.001)$. Finally, $20.1 \%$ of children suffered from flat foot and $22.6 \%$ of them had high foot arch.
\end{abstract}

Conclusion: The majority of female students in Tehran suffered from at least one or two stature and skeletal abnFormalities. The timely detection of the problem can prevent the progress and complications of these disorders.

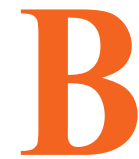

\section{Background}

ody quality and physical structure are of particular importance to humans. Body changes and deformities will affect human health so that the consequences of incorrect posture on the mental, physical, and economic aspects are worthy of investigation (Rahimi \& Hassanpour 2007). Stature structure con-

\section{* Corresponding Author:}

Leili Borimnejad, $\mathbf{P h D}$

Address: Center for Nursing Care Research, School of Nursing \& Midwifery, Iran University of Medical Sciences, Tehran, Iran. Tel: +98 (912) 5029548

E-mail:l.borimnejad@gmail.com 
nects different body parts with the center of gravity and in terms of the orthopedics, it is an index that determines mechanical efficiency of the neuromuscular system. By definition, a good stature maintains skeletomuscular balance to protect the body elements against injures or progressive distortion. This status holds in all situations whether the body is resting or performing activities. A common problem in early adolescence is skeletal disorder, which has international dimension to the extent that structural and postural abnormalities screening programs are in the agenda of schools in different countries for years (Rahnama et al. 2010).

Common abnormalities include uneven shoulder, forward head, tilted shoulder, lordosis, kyphosis, valgus deformity, knee parenthesis, flat foot, and scoliosis (Akbarfahimi et al. 2009). According to studies, the most obvious problem following structural abnormalities of stature in the students is pain. Based on the reports, the prevalence of pain in students due to musculoskeletal disorders in different organs is between $2.9 \%$ and $18.9 \%$ (Shamsedini et al. 2011). Numerous studies also investigated the cost effectiveness of these problems which further emphasizes the need for screening programs in schools.

Experts believe that on average, each Iranian student suffers from at least one or two stature problems such as hyperlordosis, parenthesis legs, and abnormal curvature of the spine. Thus, more attention should be paid to these disorders and prevent their occurrence as far as possible (Saneh 2009). Previous studies have also shown that delay in diagnosis and timely treatment of musculoskeletal disorders can lead to physical and psychological effects in girls more than boys (Danielsson et al. 2010; Payne et al. 1997). Review of studies conducted in Iran showed that despite the specific importance of the subject, a few studies have been conducted on this population. Considering the above issues, the current study was conducted to evaluate the structure of stature and its relationship with some demographic characteristics of female school students in Tehran, Iran.

\section{Materials \& Methods}

This study was a cross-sectional and descriptive study. After approving the project by Ethics Committee of Iran University of Medical Sciences, and selection of the samples, written consent forms were obtained from their parents and verbal consent obtained from children. According to Education and Training organization in the West of Tehran, 35000 students study in Tehran elementary schools, $46 \%$ of them are girls who are studying in 110 urban schools. The required sample size comprised
280 students, calculated according to the study power of 80 and a significance level of 0.05 .

By referring to the Education and Training Organization of Tehran, a list of elementary girl schools was extracted. Then, 10 schools in different parts of the West of Tehran $(2,3$, and 6 districts) were selected and out of them, students of 10 to 12 years old were selected by cluster random sampling method. The skeletal structure of these students were evaluated using body analysis software, which was the main study tool. After taking participants' digital photos from three angles of front, side, and rear and marking different parts of the body by the researcher, photos were input to the computer and by connecting the marker lines, this software reported the degree and severity of each defect.

It also uses the Libra balance which includes a steel bar with two parallel bars and a measuring meter to measure the height and weight of each student. To reduce human error in measurements, simultaneous observation and measuring of the subjects was done with the help of two researchers. As body mass index (BMI) is an important indicator of the health in children and predictive criterion in skeletal disorders, we used the CDC (Centers for Disease Control and Prevention) standards to determine BMI. Calculation of this index in children can be gender-specific. The second part of the information i.e., the demographic characteristics was collected using a questionnaire and results of which were analyzed using descriptive statistics with SPSS version 16.

\section{Results}

The demographic characteristics of 283 students participating in the research and their anthropometric characteristics are presented in Table 1. Based on BMI results, 27.6\% of students $(n=76)$ had overweight and 9.2\% $(n=26)$ suffered from underweight. According to the CDC standards, the highest percentage of obesity was $39.7 \%$ in the 12 years old age group and the most frequent underweight $(8.2 \%)$ were in the age group of 10 years old. About $1.8 \%(n=5)$ of children suffered from forward head, and $8.1 \%(n=23)$ suffered from drooping shoulder. Also, 5.7\%(n=16) of children, suffered from hallux valgus. The Chi-squared test showed a significant relationship between hallux valgus and age group $(\mathrm{P}=0.001)$. About $20.1 \%$ of children suffered from the flat foot and $22.6 \%$ from high arch foot. Kendall test showed a significant relationship between BMI and flat foot in subjects $(\mathrm{P}=0.000)$ (Table 3$)$.

As Table 2 shows, the highest prevalence of lumbar disorders in all study groups belonged to lordosis (17.3\%) and the least disorder was kyphosis $(2.5 \%)$. Knee disorders in girls under study was lower than most other 
Table 1. Anthropometric indices of female students in selected school districts in Tehran in 2013.

\begin{tabular}{ccccc}
\hline Variable & Min & Max & Mean & SD \\
\hline Age, $y$ & 10 & 12 & 11.24 & 0.587 \\
Weight, $\mathrm{kg}$ & 20 & 85 & 38.57 & 10.213 \\
Height, $\mathrm{cm}$ & 125 & 166 & 142.3 & 7.981 \\
BMI, $\mathrm{kg} / \mathrm{m}^{2}$ & 11.4 & 34.5 & 18.80 & 3597.0 \\
\hline
\end{tabular}

Table 2. Distribution of lumbar disorders in female school students in selected schools of Tehran in 2013.

\begin{tabular}{|c|c|c|c|c|c|c|}
\hline & \multicolumn{6}{|c|}{ Posture of spinal cords } \\
\hline \multicolumn{2}{|c|}{ Age, y } & \multirow{2}{*}{$\begin{array}{c}\text { Normal } \\
13\end{array}$} & \multirow{2}{*}{$\begin{array}{c}\text { Scoliosis } \\
0\end{array}$} & \multirow{2}{*}{$\begin{array}{c}\text { Kyphosis } \\
0\end{array}$} & \multirow{2}{*}{$\begin{array}{c}\text { Lordosis } \\
10\end{array}$} & \multirow{2}{*}{$\begin{array}{r}\text { Tota } \\
23\end{array}$} \\
\hline & No. & & & & & \\
\hline 10 & & & & & & \\
\hline & $\%$ & 56.5 & 0 & 0 & 43.5 & 100 \\
\hline \multirow{3}{*}{11} & No. & 126 & 15 & 5 & 24 & 170 \\
\hline & & & & & & \\
\hline & $\%$ & 71.4 & 8.8 & 2.9 & 14.1 & 100 \\
\hline \multirow[b]{2}{*}{12} & No. & 69 & 4 & 2 & 15 & 90 \\
\hline & O & 767 & & 27 & 167 & 100 \\
\hline \multirow{4}{*}{ Total } & No. & 208 & 19 & 7 & 49 & 283 \\
\hline & & & & & & \\
\hline & $\%$ & 73.5 & 6.7 & 2.5 & 17.3 & 100 \\
\hline & & $\chi^{2}=1.65$ & $P=0.018$ & $d f=6$ & & \\
\hline
\end{tabular}

Client-Centered Nursing Care

Table 3. The relationship between demographic characteristics and structural disorders of stature in 10-12 years old female students in 2013.

\begin{tabular}{|c|c|c|c|c|}
\hline \multicolumn{2}{|c|}{ Variable } & P-value & df & Statistical test \\
\hline Hallux valgus & Age & 0.004 & 2 & $\chi^{2}=11.003$ \\
\hline Flat foot & BMI & 0.003 & 109 & $F=1.58$ \\
\hline
\end{tabular}

Client-Centered Nursing Care

disorders, so that $0.7 \%(n=2)$ had valgus deformity and $1.8 \%(n=5)$ had parenthesis knee.

\section{Discussion}

This study is the first comprehensive skeletal screening using the organ analysis software which showed various skeletal disorders in 10-12 years old girls in Tehran, Iran. According to the results, only $6 \%$ of students $(n=17)$ had no disorder and the rest of students had at least one disorder. Two students suffered from 7 disorders simultaneously. In a similar study in Belgrade conducted on the same age group, $76 \%$ of students had no disorder (Petrović et al. 2012). Comparing the results of the two studies indicates a high prevalence of musculoskeletal disorders among female students in Tehran.

Based on previous research, the underlying causes for skeletal disorders are obesity and overweight. In the current study, $27.4 \%$ of children were obese. In a study con- 
ducted in 2002 in Tehran, the prevalence of overweight and obesity in this age group was $21 \%$ (Mozaffari \& Naba'i 2003). Comparing results of these two studies shows increasing prevalence of obesity in this age group.

In this study, prevalence of forward head was $1.8 \%$. In this disorder, the center of gravity of the head is placed ahead of the plumb line and evidently the cervical lordosis increases. In this disorder, a lot of pressure is exerted on the neck joints, because torque force increases on the spinal cord. Its complications are pain, unpleasant appearance, shortness of height, too much pressure on cervical cord and nerves, too much pressure on the temporomandibular area, dropped chest and shoulders, and imbalance. Forward head syndrome, if left untreated, leads to the rotation of shoulders to the inside and hunchback in long term. Thus, people should correct their wrong habits and learn how to sit and use tools properly. Because with disease progression and inflicting with arthritis, treatment will be much more difficult. While early diagnosis of this problem and performing corrective exercises can prevent these complications. A similar study that evaluated the prevalence of the problem in this age group has been not found. In the study by Saneh conducted on secondary school students, the prevalence of this disorder was reported to be $4.2 \%$, along with poor body condition (Saneh 2009).

Another problem addressed in the present study, was lumbar disorders. The highest prevalent lumbar disorder in all children under study was lordosis (17.3\%) and the least disorder was kyphosis (2.5\%). The only Iranian study, which addressed the prevalence of kyphosis, was conducted on secondary school age children in Kurdistan Province in 2003. In which the prevalence of this problem was reported to be $2.4 \%$ (Rezaei et al. 2004). Although the best time to diagnose lumbar disorders and take appropriate action is at the age of 10-12, no research was found which screen this problem in this age group in Iran. The study conducted in Belgrade has reported the problem in elementary school children to be $10.5 \%$ and according to other authors, this figure is various in different societies and ranges from $4 \%$ to $51.4 \%$. The reason for these differences relates to sitting habits and ergonomics culture on different places (Petrović et al. 2012).

In this study, the prevalence of scoliosis was $6.7 \%$. Based on a study conducted by Rezaei et el. in Kermanshah Province, this disorder was reported to be $1.4 \%$ with a higher incidence in girls, while in a study in Minnesota, USA in 2008, this figure was between $0.59 \%$ and $7.7 \%$. This difference was attributed to different measurement tools. In the same report, prevalence of scoliosis in girls was higher than boys and researchers recommended screening of 10-12 years old girls in all schools (Rezaei et al. 2004).

In drooping shoulders, the shoulders are hanging downwards and person is not in so-called broad-shouldered posture which in addition to the unpleasant appearance, creates neck and back pain. In this study, $8.1 \%$ of children had this problem. Considering the gender and age of these children, if timely action is not taken, their mental images from themselves will be affected. The results of a study by Saneh (2009) conducted in the district 2 of Tehran in middle school students were significantly different from the current study results. According to the results, the uneven shoulder in the girls was $85.3 \%$ in which $1.9 \%$ of students were in poor physical condition (Saneh 2009). Previous studies on the causes of this problem mentioned the weight of the bag and its inappropriate carrying. It seems that teaching children and families regarding this issue is essential (Patel et al. 2011; Whittfield et al. 2005).

The prevalence of hallux valgus in this study was $16 \%$ which was similar to the study in Bayangan (Mirzaee \& Salimi 2012). In a study conducted in Bayangan in Kermanshah Province, the prevalence of this disorder in girls of 11 to 15 years of age was reported to be $47.5 \%$.

In this research, $20 \%$ of students suffered from flat foot. Studies have been conducted in different cities of Iran reported the prevalence of this disorder in the age group of 7 to 14 as $6.9 \%$. In a study in Nigeria this figure was $18.2 \%$ among rural students and 32\% among urban students (Abolarin et al. 2011). There was also a significant association between BMI and flatfoot in study subjects $(\mathrm{P}=0.000)$ which confirms the results of the study by Chen et al. (2009), Chang et al. (2010), and Evans and Rome (2011). Cousins et al. (2013) in their research investigated the pattern of flat foot in 7 to 11 years children with fat, overweight, and normal body index. The researchers concluded that pressure imposed on the middle area and the second to the fifth metatarsal bones change the arc of the child's foot and increase flat foot in these children.

According to the research results, the majority of female elementary students in Tehran suffer from at least one or two stature and skeletal abnormalities. In implementing screening programs to identify students with postural abnormalities, holding training classes for physical education teachers and educators, assessment and treatment of postural abnormalities by offering different solutions such as standardization of desk and benches in 
schools, and establishing advanced centers for prevention and treatment of structural abnormalities are suggested to reduce the rate of these problems. Despite the attention to postural abnormalities, these studies lack enough cohesion and researchers have presented various statistics in their studies.

School nurse is the most important person who can prevent complications and progress of these problems by timely detection of them. The reason for importance of school nurse role is that skeletal problems in childhood are most often benign and self-limiting and most of the time they can be corrected with a series of exercises and training. Explaining the position of school nurse in Education and Training organization can be proposed in policy making fields. The role of physical training instructor in education and reform training of students is undeniable. Because by timely detection of this problem and delivering appropriate training to students, referring to higher levels is not necessary and in addition to maintain the child's physical strength, mental stress resulting from having different appearance is certainly prevented. Several studies have also shown that screening and timely action can significantly reduce the amount of healthcare costs and absence from school and absenteeism of parents.

\section{Acknowledgements}

We sincerely express our gratitude to education officials in Tehran and school administrators who offered selfless cooperation in the implementation of the study. We thank the Vice Chancellor for Research of Iran University of Medical Sciences and the Research Center for Nursing Care who financially supported this research.

\section{Conflict of Interest}

The authors declared no conflict of interests.

\section{Reference}

Abolarin, TO, Aiyegbusi, AI, Tella, BA \& Akinbo, SR 2011, 'Relationship between selected anthropometric variables and prevalence of flatfoot among urban and rural school children in south west Nigeria', Nigerian Quarterly Journal of Hospital Medicine, vol. 21, no. 2, pp. 135-40. PMID: 21913511

Akbarfahimi, N, Jadidi, B, Shahi, Z \& Jadidi, H 2009, '[The impact of exercise therapy on the musculoskeletal abnormalities of blind boy students of 12-18 years old at Tehran Mohebbi blind school [Persian]', Koomesh, vol. 10, no. 4, pp. 307-13.

Chang, JH, Wang, SH, Kuo, CL, Shen, HC, Hong, YW \& Lin, LC 2010, 'Prevalence of flexible flatfoot in Taiwanese school- aged children in relation to obesity, gender, and age, European Journal of Pediatrics, vol. 169, no. 4, pp. 447-52. doi: 10.1007/ s00431-009-1050-9

Chen, JP, Chung, MJ \& Wang, MJ 2009, 'Flatfoot prevalence and foot dimensions of 5- to 13-year-old children in Taiwan', Foot Ankle International, vol. 30, no. 4, pp. 326-32. doi: 10.3113/ FAI.2009.0326.

Cousins, SD, Morrison, SC \& Drechsler, WI 2013, 'Foot loading patterns in normal weight, overweight and obese children aged 7 to 11 years', Journal of Foot $\mathcal{E}$ Ankle Research, vol. 6, pp. 36. doi: 10.1186/1757-1146-6-36

Danielsson, AJ, Hasserius, R, Ohlin, A \& Nachemson, AL 2010, 'Health-related quality of life in untreated versus brace-treated patients with adolescent idiopathic scoliosis a long-term follow-up', Spine, vol. 35, no. 2, pp. 199-205. doi: 10.1097/ BRS.0b013e3181c89f4a

Evans, AM \& Rome, KA 2011, 'Cochrane review of the evidence for non-surgical interventions for flexible pediatric flat feet', European Journal of Physical \& Rehabilitation Medicine, vol. 47, no. 1, pp. 69-89. PMID: 21448121

Patel, J, Walker, JL, Talwalkar, VR, Iwinski, HJ \& Milbrandt, TA 2011, 'Milbrand correlation of spine deformity, lung function, and seat pressure in Spina Bifida, Clinical Orthopaedics \& Related Research, vol. 469, no. 5, pp. 1302-307. doi: 10.1007/ s11999-010-1687-8

Mirzaee, R \& Salimi N, 2012, '[Survey of prevalence of skeletal disorders in student at Bayangan Kermanshah (Persian)]', Journal of Kermanshah University of Medical Sciences, vol. 16, no. 7, pp. 565-57.

Mozaffari, R \& Naba'i, B 2003, '[Survey the prevalence of obesity in female students at primary school in Tehran (Persian)]', Payesh, vol. 1, no. 4, pp. 15-19.

Payne, WK, Ogilvie, JW, Resnick, MD, Kane, RL, Transfeldt, EE \& Blum, RW 1997, 'Does scoliosis have a psychological impact and does gender make a difference?', Spine, vol. 22, no. 12, pp. 1380-384. PMID: 9201842

Petrović, J, Puzović, V, Djordjevic D, Obrenovic M, Medic, V \& Jakovljevic, V 2012, 'Prevalence of spine deformity among 7-11 year old children', Medicinski časopis, vol. 46, no. 4, pp. 187-90. doi: $10.5937 /$ mckg46-1712

Rahimi Gh \& Hassanpour M, 2007, 'IInvestigation effect of 8 weeks corrective exercise on curved lumber in female students age between 19-25 (Persian)]', Harkat, vol. 29, no. 5, pp. 69-86.

Rahnama, N, Bambaeichi, E, Taghian, F, Nazarian, AB \& Abdollahi, M 2010, 'Effect of 8 weeks regular corrective exercise on spinal columns deformities in girl students (Persian)]', Journal of Isfahan Medical School, vol. 27, no. 101, pp. 675-86.

Rezaei, S, Rezaei, M, Pourbiazar, M, Hydarian, N \& Farshchian, M 2004, '[Prevalence of Kyphosis among the Secondary Students of Kermanshah city (Persian)]', Journal of Ilam University of Medical Sciences, vol. 13, no. 2, pp. 32-43.

Saneh, A 2009, '[A comparison between guidance school' girls and boys on the prevalence of the upper organs' postural abnormalities (Persian)]', Quarterly Journal of Educational Innovations, vol. 8, no. 3, pp. 139-56. 
Shamsedini, A, Hellisaz, MT, Dalvand, H, Khatibi, AD \& Sobhani, V 2011, '[The investigation of prevalence of musculoskeletal symptoms and discomfort caused by them in students of Tehran (Persian)]', Journal of Ardabil University of Medical Sciences, vol. 8, no. 4, pp. 271-76

Whittfield, J, Legg, SJ \& Hedderley, DI 2005, 'Schoolbag weight and musculoskeletal symptoms in New Zealand secondary schools', Applied Ergonomics, vol. 36, no. 2, pp. 193-98. doi: 10.1016/j.apergo.2004.10.004 